\title{
Estimation of average value at risk (AVaR) on sharia joint-stock index using Glosten, Jaggnathan and Runkle (GJR) model
}

\author{
Sri Muslihah Bakhtiar ${ }^{1}$ Ermawati $^{2}$ Ilham Syata ${ }^{3, *}$ Wahidah Alwi ${ }^{4}$ \\ Risnawati Ibnas ${ }^{5}$ Sri Dewi Anugrawati ${ }^{6}$ \\ 1.2.3.4.5,6 Mathematics Department, Universitas Islam Negeri Alauddin Makassar \\ *Corresponding author. Email: ilham.syata@uin-alauddin.ac.id
}

\begin{abstract}
The average value at risk ( $\mathrm{AVaR})$ is a measuring tool used to assess the worst loss experienced by an investor on a portfolio investment at a certain time. Furthermore. AVaR's level of confidence needs to fulfill all the axioms regarding the nature of risk for risk-varse investors. This is because the possibility of an asymmetric volatility response can be overcomed by estimating the risk of loss using the Glosten. Jagganathan. and Runkle (GJR) models. In this study. the stock price data for the period January 1-28 December 2018 were used for the response. Therefore. this study aims to determine the risk estimation of stock price loss using the Average Value at Risk with the Glosten Jagganathan and Runkle models. The results showed that the stock price obtained from the AVaR estimation with a $95 \%$ confidence level of $0.1627 \%$ may be experienced one day ahead.
\end{abstract}

Keywords: GJR-GARCH, Asymmetric, AVaR

\section{INTRODUCTION}

Investment has a very significant role in the movement of the economy. Economic growth cannot be separated from the influence of capital market developments so that the capital market can facilitate people to invest. An investor will buy several shares in the hope of making a profit. However. investing will be accompanied by risks. especially with a large enough investment.

One of the measuring tools commonly used by investors and quite popular is Value at Risk (VaR). VaR is used as a measuring tool that can assess the worst loss experienced by an investor in investing in a portfolio at a certain time and level of confidence. VaR has become a commonly used risk measure for financial risk management because the concept is quite simple. easy to calculate. and can be applied directly. However.
VaR has several deficiencies that are recognized by experts in the financial sector. among others. VaR only measures the percentile of the distribution of profits or losses without considering any losses that exceed the VaR level. Therefore. we need a measuring tool that can overcome the weaknesses of $\mathrm{VaR}$ to provide more accurate results. namely Average Value at Risk (AVaR). AVaR is a measurement tool that has advantages over $\mathrm{VaR}$. One of the advantages of $\mathrm{AVaR}$ is that it fulfills all the axioms regarding the nature of risk which is coherent and consistent about investors who are risk-averse [1].

Stock prices that fluctuate every day provide uncertainty to investors who invest in returns that are random and have high volatility or variance is not constant (heteroscedasticity). Heteroscedasticity. which is indicated by the presence of instability in volatility. has led to volatility clustering that is a phenomenon where 
volatility will remain at a high level for several periods when volatility is trending up or vice versa and it will remain low for several periods when volatility is trending down. With this problem. a series model that can maintain the heteroscedasticity of data is needed such as the GARCH model [2]

The GARCH model can be used to estimate the maximum potential loss that will occur in the future with a certain time and a certain level of confidence. However the effect of asymmetry is often found. This GARCH model is unable to fulfill all asymmetric responses to shocks. This asymmetric response is known as the leverage effect so that the GARCH model is developed to meet the possibility of an asymmetric volatility response. The development of this GARCH Model is the GJR Model introduced by Glosten. Jagannathan. and Runkle in 1993 [3].

Previous research conducted by Komang D[1]on the estimation of AVaR (Average Value at Risk) using the GJR Model and the GARCH Model to estimates the $\mathrm{VaR}$ and $\mathrm{AVaR}$ values and then compares the performance of the two models. The test results show that the $\mathrm{VaR}$ and $\mathrm{AVaR}$ with the GJR Model approach provide higher aggressiveness when compared to the GARCH model. The research conducted by Dinul D J [5] who also compared the GJR-GARCH model with the EGARCH model in the risk analysis of Islamic stocks . This research states that the measurement of risk by using VaR with the GJR model shows the risk value for the composite index of Islamic stocks is smaller than using VaR-EGARCH. Therefore. based on the explanation before. we think its important to estimate the Average Value at Risk (AVaR) using the Jagganathan and Runkle (GJR) Glosten Model.

\section{METHODOLOGY}

\subsection{GARCH Model}

The ARCH model is generally used to estimate the volatility introduced by Engle in 1982 whose residuals are not correlated. Then Tim [4] develops the ARCH model into a GARCH model of residual money following the GARCH model $(p . q)$ where $q$ is the ARCH order and $p$ is the GARCH order. This GARCH model has the characteristic of symmetrical volatility to shocks. Or it can be said that as long as the intensity is the same. the volatility response to a shock is the same. whether it is a positive shock (good news) or negative (bad news). The general form of the GARCH model $(p . q)$

$$
\sigma_{t}^{2}=\alpha_{0}+\alpha_{1} \varepsilon_{t-1}^{2}+\ldots+\alpha_{i} \varepsilon_{t-p}^{2}+\beta_{1} \sigma_{t-1}^{2}+\ldots+\beta_{j} \sigma_{t-q}^{2}
$$

Where $\boldsymbol{\alpha}_{\mathbf{0}}$ is constant. $\boldsymbol{\beta}_{\boldsymbol{j}}$ is GARCH parameter. $\boldsymbol{\beta}_{\boldsymbol{i}}$ is ARCH parameter. and $\boldsymbol{\epsilon}_{\boldsymbol{t}}$ is white noise process

\subsection{Asymmetric Test}

The asymmetric test is a property that shows the imbalance of certain conditions or objects. In time series analysis. the asymmetric nature can be interpreted as a "leverage effect" or an imbalance in price movement patterns (high volatility). This condition is very risky in determining decision making. Therefore. it is necessary to perform the test of data asymmetry for determining the presence or absence of asymmetric symptoms in the data by looking at the values of skewness and kurtosis. This skewness is a degree imbalance in the distribution. If the skewness which measures the asymmetry of the data distribution is not equal to zero then the distribution is said to be asymmetrical (asymmetric) and if the skewness is equal to zero then the data is normally distributed (symmetrical)[5]

\subsection{GJR-GARCH Model}

Glosten. Jagannathan. and Runkle introduced the Asymmetric GARCH (AGARCH) model or better known as the GJR-GARCH. One of the advantages of the GJR-GARCH model is to measure volatility due to the different effects of bad news and good news. GJRGARCH is an extension of the GARCH modeling technique. where a variable is added to the conditional variance equation to accommodate the possibility of asymmetry in the volatility of a variable as a result of bad news and good news. The GJR model slightly differs from the GARCH model where the GJR model has a part that represents the asymmetry. it's represented by the parameter as in the following equation:

$$
r_{t}=c_{0}+c_{1} r_{t-1}+\varepsilon_{t}
$$

Where $\varepsilon_{t}$ is the residual of the model. Furthermore

$$
\begin{aligned}
\sigma_{t}^{2} & =\alpha_{0}+\alpha_{1} \sigma_{t-1}^{2}+\alpha_{2} \sigma_{t-2}^{2}+\alpha_{3} \sigma_{t-3}^{2}+\ldots+\alpha_{p} \sigma_{t-p}^{2} \\
\sigma_{t}^{2} & =\alpha_{0}+\alpha_{1} \varepsilon_{t-1}^{2}+\ldots+\alpha_{i} \varepsilon_{t-i}^{2}+\beta_{1} \sigma_{t-1}^{2}+\ldots \\
& +\beta_{j} \sigma_{t-j}^{2}+\gamma I_{t-1} \varepsilon_{t-1}^{2}+\ldots+\gamma I_{t-k} \varepsilon_{t-i}^{2}
\end{aligned}
$$

Or

$$
\sigma_{t}^{2}=\alpha_{0}+\sum_{i=1}^{P} \alpha_{i} \varepsilon_{t-i}^{2}+\sum_{j=1}^{Q} \beta_{j} \sigma_{t-j}^{2}+\sum_{k=1}^{P} \gamma I_{t-k} \varepsilon_{t-i}^{2}
$$

Where $z_{t} \square N(0,1)$ or $z_{t} \square t_{d}$ and

$I_{t-1}=\left\{\begin{array}{l}1, \varepsilon_{t-1}<0 \\ 0, \varepsilon_{t-1} \geq 0\end{array}\right.$ 
With $\alpha_{0}>0 . \alpha_{1} \geq 0 . \beta \geq 0 . \beta+\gamma \geq 0 . \alpha_{1}+\frac{1}{2} \gamma<1$. and $I_{t-1}$ is a dummy variable. When $\gamma$ is positive it means that tomorrow's volatility is more negative if today's residual is negative. GJR-GARCH model is an asymmetric GARCH model so estimating parameters $\alpha_{0} \cdot \alpha_{1} \cdot \beta_{j}$.and

$\gamma_{i}$ can be done by using the Maximum Likelihood method which assumes the stock price index returns are normally distributed [1].

\subsection{Akaike information Criterion (AIC) Test}

AIC is used to select the best model. If two models are compared. the smallest AIC model is the best model [6]. The AIC formula is as follows:

$$
A I C=n \ln \sigma_{a}^{2}+\frac{2 k}{n}
$$

where $\sigma_{a}^{2}$ is the maximum likelihood estimate of $\sigma_{a}^{2} . K$ is the number of parameters in the model and $n$ is the number of samples.

\subsection{Value at Risk (VaR)}

Value at Risk ( $\mathrm{VaR}$ ) is a measurement to estimate the maximum loss that will be obtained during a certain period in normal market conditions at a certain level of confidence. VaR at the confidence level $(1-\alpha)$ and the time interval $t$ can be formulated as follows:

$$
\operatorname{VaR}_{t}(\alpha)=\inf \left\{r_{t}: F_{t}\left(r_{t}\right) \geq \alpha\right\}
$$

Where $F t$ is the distribution function of the rate of return on asset return $r_{t}$ at time $t$. Thus. the $\mathrm{VaR}$ for the next day at the confidence level $\alpha$ can be formulated as follows:

$$
\operatorname{VaR}_{t}=\mu+\sigma_{t} \Phi^{-1}(\alpha)
$$

where $\Phi^{-1}($.$) is the inverse function of the standard$ normal cumulative distribution function [7]

\subsection{Average Value at Risk (AVaR)}

Average Value at Risk (AVaR) is the main alternative in measuring risk which serves to reduce problems that occur in $\mathrm{VaR}$. This $A V a R$ is the conditional expectation of the tail of the distribution where $\mathrm{VaR}$ is a quantile. The two risk measures are identical if the tail of the distribution of the random variable is missing. AVaR has a coherent nature so it is more interesting to explore from a mathematical point of view. Due to these characteristics. AVaR is better and easier to optimize with linear programming methods when compared to VaR. AVaR with the confidence level $\alpha 2[0 ; 1]$ and the function of the return distribution is assumed to have a continuous function. then the equation can be written as follows:

$$
\begin{aligned}
\operatorname{AVaR}_{\alpha}(r) & =-\frac{1}{\alpha} \int_{0}^{\alpha} F_{r}^{-1}(s) d s \\
& =-E\left(r_{t} \mid r_{t} \leq \operatorname{VaR}_{\alpha}\left(r_{t}\right)\right)
\end{aligned}
$$

where $\boldsymbol{F}_{\boldsymbol{r}}{ }^{-1}$ is the inverse of a distribution function of $\alpha$

\section{RESULT AND DISCUSSION}

The data used in this study is the combined share price of sharia stock in the period 1 st January 2018 to 28 December 2018. The skewness value is obtained a negative value namely -0.1652389 that is mean the data distribution more and longer on the left which indicates that there is an asymmetrical character data. Furthermore the value of kurtosis is 4.415314 . It's means that the data has a high enough volatility because the value is above the value of 3 which causes the symptom of heteroscedasticity in the data. Time series data cannot be separated from the stationarity test of the data to be studied. Therefore a stationary test was performed. Stationarity data testing was carried out through the unit root test statistical test using the Augmented Dickey Fuller (ADF) method so that the data can be said to be not stationary. The way for making stationary returns can be done by using differencing order 1 to the return. The results of the first-order differencing was plotted in the following figure:

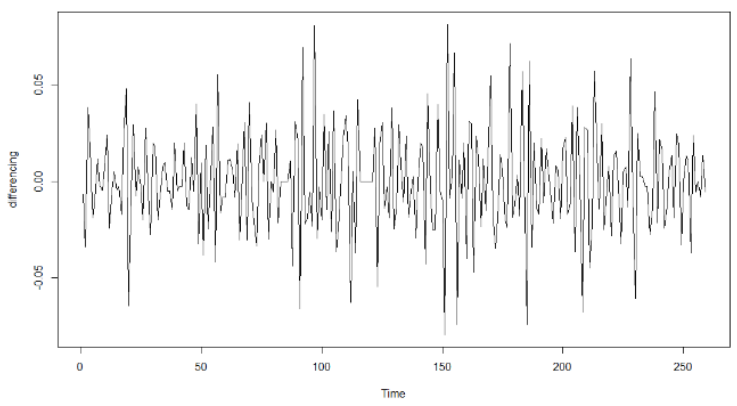

Figure 1. The first order differencing data plot of stock returns

The data stationarity test used Augmented Dickey Fuller (ADF) method. From the test results we obtained a p-value of 0.01. This value is smaller than the significant level of 5\%. Because the p-value $<\alpha$ than $H_{o}$ is rejected which means that the data resulting from the first-order differencing is stationary.

The stock price index return data is tested for normality to determine whether the data is normally distributed or not. The return data normality test can be 
done by looking at the normality test chart and through the Jarque-Bera test. The graph of normality test data can be seen in the following figure:

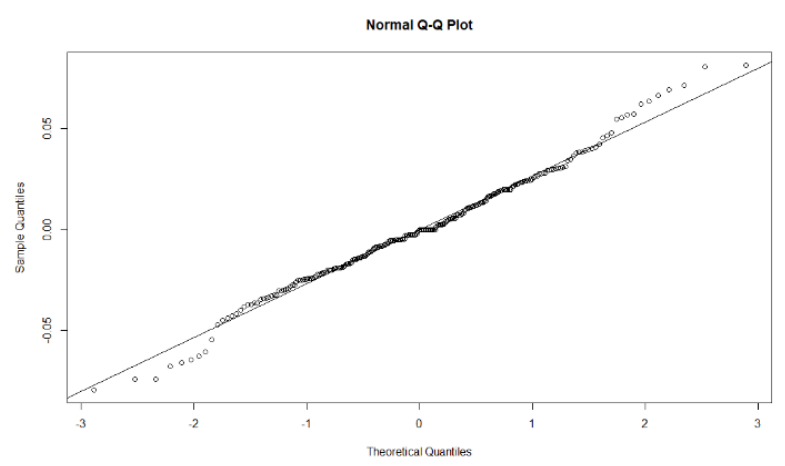

Based on the normality test of stock return data. it can be seen that the data spread around the diagonal line and follows the direction of the diagonal line or histogram graph so that the data can be said to be normally distributed.

\subsection{ARIMA(p.d.q) Model}

After identifying the ARIMA model (p.d.q). the ARIMA model parameter estimation process $(p . d . q)$ is carried out. ARIMA model estimates can be seen in the following table 1. Based on table 1. we get that the best ARIMA (p. $d . q)$ model is ARIMA (2.1.2). The criteria for the model are seen based on the smallest AIC value. which is -1273.25 so that the model can be used for the next stage.

Figure 2. Normality test of stock return data

Table 1. ARIMA (p.d. q) model

\begin{tabular}{|c|c|c|c|c|}
\hline Model & Parameter & Estimate & SE & AIC \\
\hline ARIMA(1.1.0) & AR 1 & -0.595 & 0.0498 & -961.66 \\
\hline \multirow[t]{2}{*}{ ARIMA(1.1.1) } & AR 1 & -0.4184 & 0.0564 & \multirow{2}{*}{-1160.4} \\
\hline & MA 1 & -1 & 0.0096 & \\
\hline \multirow[t]{3}{*}{$\operatorname{ARIMA(1.1.2)}$} & AR 1 & 0.0272 & 0.063 & \multirow{3}{*}{-1270.9} \\
\hline & MA 1 & -1.9992 & ----- & \\
\hline & MA 2 & 0.9998 & ----- & \\
\hline \multirow[t]{2}{*}{$\operatorname{ARIMA(2.1.0)}$} & AR 1 & -0.9189 & 0.0521 & \multirow{2}{*}{-1050} \\
\hline & AR 2 & -0.5441 & 0.0521 & \\
\hline \multirow[t]{3}{*}{$\operatorname{ARIMA(2.1.1)}$} & AR 1 & -0.5883 & 0.0571 & \multirow{3}{*}{-1202.7} \\
\hline & AR 2 & -0.3978 & 0.0571 & \\
\hline & MA 1 & -1 & 0.0097 & \\
\hline \multirow[t]{4}{*}{$\operatorname{ARIMA(2.1.2)}$} & AR 1 & 0.0255 & 0.0624 & \multirow{4}{*}{-1273.3} \\
\hline & AR 2 & -0.1298 & 0.0622 & \\
\hline & MA 1 & -1.9945 & ----- & \\
\hline & MA 2 & 0.9949 & ----- & \\
\hline \multirow[t]{3}{*}{$\operatorname{ARIMA(3.1.0)}$} & AR 1 & -1.1161 & 0.0581 & \multirow{3}{*}{-1083.7} \\
\hline & AR 2 & -0.8772 & 0.0581 & \\
\hline & AR 3 & -0.36 & 0.0581 & \\
\hline \multirow[t]{4}{*}{ ARIMA(3.1.1) } & AR 1 & -0.6703 & 0.061 & \multirow{4}{*}{-1211.6} \\
\hline & AR 2 & 0.5185 & 0.0664 & \\
\hline & AR 3 & -0.2037 & 0.061 & \\
\hline & MA 1 & -1 & 0.0098 & \\
\hline \multirow[t]{5}{*}{$\operatorname{ARIMA(3.1.2)}$} & AR 1 & 0.0293 & 0.0633 & \multirow{5}{*}{-1271.4} \\
\hline & AR 2 & -0.1288 & 0.0622 & \\
\hline & AR 3 & 0.0194 & 0.0633 & \\
\hline & MA 1 & -1.9667 & ----- & \\
\hline & MA 2 & 0.9972 & ----- & \\
\hline \multirow[t]{4}{*}{$\operatorname{ARIMA(4.1.0)}$} & AR 1 & -1.2409 & 0.0584 & \multirow{4}{*}{-1114.4} \\
\hline & AR 2 & -1.1805 & 0.0851 & \\
\hline & AR 3 & -0.7467 & 0.085 & \\
\hline & AR 4 & -0.3447 & 0.0583 & \\
\hline$\cdots$ & $\cdots$ & $\cdots$ & .. & \multirow{7}{*}{-1267.6} \\
\hline \multirow{6}{*}{$\operatorname{ARIMA(6.1.2)}$} & AR 1 & 0.0302 & 0.0635 & \\
\hline & AR 2 & -0.144 & 0.0633 & \\
\hline & AR 3 & 0.0205 & 0.064 & \\
\hline & AR 4 & -0.0949 & 0.0638 & \\
\hline & AR 5 & 0.0004 & 0.0632 & \\
\hline & AR 6 & -0.0257 & 0.063 & \\
\hline
\end{tabular}




\begin{tabular}{lcc} 
MA 1 & -1.9947 & ---- \\
MA 2 & 0.995 & ---- \\
\hline
\end{tabular}

\subsection{Estimation of GARCH parameter}

GARCH modeling is a model that is done to solve problems with heteroscedastic data or there is an effect of ARCH on the ARIMA(p. d. q) model. Based on the ARIMA (2.1.2) model which is the best ARIMA model. the identification of the GARCH (p. q) model uses the order $\mathrm{p}$ and $\mathrm{q}$ of 2 . namely GARCH (1.1). GARCH (1.2).
GARCH (2. 1). GARCH (2.2). The GARCH (p. q) model estimates can be seen in the table 2 .

Based on table 2. the best GARCH (p.q) model is GARCH (1.1). The criteria for the model were seen based on the smallest AIC value. which was -4.914337 so that the model could be used for the next stage.

Table 2. GARCH (p.q) model

\begin{tabular}{|c|c|c|c|c|}
\hline Model & Parameter & Estimate & S.E & AIC \\
\hline \multirow{6}{*}{ GARCH(1.1) } & $\mu$ & $2.218 \mathrm{E}-20$ & 0.00018 & \multirow{6}{*}{-4.914337} \\
\hline & $\emptyset_{1}$ & -0.7624 & 0.1405 & \\
\hline & $\theta_{1}$ & -0.1028 & 0.07151 & \\
\hline & $\omega$ & -0.1468 & 0.1263 & \\
\hline & $\alpha_{1}$ & -0.7283 & 0.127 & \\
\hline & $\beta_{1}$ & 0.00004841 & 0.000106 & \\
\hline \multirow{7}{*}{ GARCH(1.2) } & $\mu$ & 2.218E-20 & 0.00018 & \multirow{7}{*}{-4.907323} \\
\hline & $\emptyset_{1}$ & -0.767 & 0.137 & \\
\hline & $\theta_{1}$ & -0.1026 & 0.07053 & \\
\hline & $\omega$ & -0.1449 & 0.1237 & \\
\hline & $\alpha_{1}$ & -0.7309 & 0.1236 & \\
\hline & $\beta_{1}$ & 0.000004422 & $4.685 \mathrm{E}-06$ & \\
\hline & $\beta_{2}$ & 0.00000001 & 0.01082 & \\
\hline \multirow{7}{*}{ GARCH(2.1) } & $\mu$ & 2.218E-20 & 0.0001832 & \multirow{7}{*}{-4.907323} \\
\hline & $\emptyset_{1}$ & -0.767 & 0.138 & \\
\hline & $\theta_{1}$ & -0.1026 & 0.06874 & \\
\hline & $\omega$ & -0.1449 & 0.1235 & \\
\hline & $\alpha_{1}$ & -0.7309 & 0.1241 & \\
\hline & $\alpha_{2}$ & 0.000004422 & ----- & \\
\hline & $\beta_{1}$ & 0.00000001 & 0.04744 & \\
\hline \multirow{8}{*}{$\operatorname{GARCH}(2.2)$} & $\mu$ & $2.218 \mathrm{E}-20$ & 0.0001927 & \multirow{8}{*}{-4.902317} \\
\hline & $\emptyset_{1}$ & -0.7554 & 0.1444 & \\
\hline & $\theta_{1}$ & -0.1065 & 0.07229 & \\
\hline & $\omega$ & -0.1468 & 0.1301 & \\
\hline & $\alpha_{1}$ & -0.7203 & 0.1314 & \\
\hline & $\alpha_{2}$ & 0.00008777 & 0.000201 & \\
\hline & $\beta_{1}$ & 0.00000001 & 0.07093 & \\
\hline & $\beta_{2}$ & 0.0347 & 0.04767 & \\
\hline
\end{tabular}

\subsection{GJR-GARCH (p.q) model}

In the previous best model. the best model ARIMA (2.1.2) GARCH (1.1) has been obtained by looking at the smallest AIC value. so that the model is used in the GJR model. Therefore by using the GJR-GARCH (1.1). GJRGARCH (1.2). GJR-GARCH (2.1). GJR-GARCH (2.2) models. the estimated results of the GJR-GARCH parameter estimation can be seen in the Following table 3.

Estimation of the GJR-GARCH model obtained the best model namely the GJR-GARCH model (1.1) that have been seen from the smallest AIC model so the ARIMA (2.1.2) and GJR GARCH (1.1) models as bellow

a. $\operatorname{ARIMA(2.1.2)~Model~}$

$$
\begin{array}{r}
Z_{t}=2.22 e^{-20}-0.7334 Z_{t-1}-0.1068 Z_{t-2} \\
-0.1678 \varepsilon_{t-1}-0.6953 \varepsilon_{t-1}-\varepsilon_{t}
\end{array}
$$

b. GJR-GARCH(1.1) Model

$$
\begin{aligned}
\sigma_{t}{ }^{2}=0.0000139 & +0.009961 \varepsilon_{t-1}{ }^{2} \\
& +0.99472{\sigma_{t-1}}^{2}+I_{t-1} \varepsilon_{t-1}{ }^{2}
\end{aligned}
$$


Table 3. GJR-GARCH (p. q) model

\begin{tabular}{|c|c|c|c|c|}
\hline Model & Parameter & Estimate & S.E & AIC \\
\hline \multirow{6}{*}{$\begin{array}{c}\text { GJR } \\
\text { GARCH(1.1) }\end{array}$} & $\mu$ & $2.22 \mathrm{E}-20$ & 0.000197 & \multirow{6}{*}{-4.916514} \\
\hline & $\emptyset_{1}$ & -0.7334 & 0.1694 & \\
\hline & $\theta_{1}$ & -0.1068 & 0.07597 & \\
\hline & $\omega$ & -0.1678 & 0.1567 & \\
\hline & $\alpha_{1}$ & -0.6953 & 0.1584 & \\
\hline & $\beta_{1}$ & $1.39 \mathrm{E}-05$ & $1.23 \mathrm{E}-05$ & \\
\hline \multirow{7}{*}{$\begin{array}{c}\text { GJR } \\
\text { GARCH } \\
(\mathbf{1 . 2 )}\end{array}$} & $\mu$ & 0.009961 & 0.01077 & \multirow{7}{*}{$\begin{array}{c}-4.907323 \\
-4.899601\end{array}$} \\
\hline & $\emptyset_{1}$ & 1 & 0.8295 & \\
\hline & $\theta_{1}$ & 0.9472 & 0.03718 & \\
\hline & $\omega$ & $2.22 \mathrm{E}-20$ & 0.00018 & \\
\hline & $\alpha_{1}$ & -0.767 & 0.1369 & \\
\hline & $\beta_{1}$ & -0.1026 & 0.07053 & \\
\hline & $\beta_{2}$ & -0.1449 & 0.1236 & \\
\hline \multirow{7}{*}{$\begin{array}{c}\text { GJR } \\
\text { GARCH } \\
(\mathbf{2 . 1})\end{array}$} & $\mu$ & -0.7309 & 0.1233 & \multirow{7}{*}{$\begin{array}{l}-4.907323 \\
-4.903036\end{array}$} \\
\hline & $\emptyset_{1}$ & $4.42 \mathrm{E}-06$ & ----- & \\
\hline & $\theta_{1}$ & $1 \mathrm{E}-08$ & ----- & \\
\hline & $\omega$ & -0.2291 & ----- & \\
\hline & $\alpha_{1}$ & 0.9897 & ----- & \\
\hline & $\alpha_{2}$ & $1 \mathrm{E}-08$ & ----- & \\
\hline & $\beta_{1}$ & $2.22 \mathrm{E}-20$ & 0.000198 & \\
\hline \multirow{8}{*}{$\begin{array}{c}\text { GJR } \\
\text { GARCH } \\
(\mathbf{2 . 2 )}\end{array}$} & $\mu$ & -0.7401 & 0.1605 & \multirow{8}{*}{-4.902317} \\
\hline & $\emptyset_{1}$ & -0.1139 & 0.07499 & \\
\hline & $\theta_{1}$ & -0.1648 & 0.1476 & \\
\hline & $\omega$ & -0.6973 & 0.149 & \\
\hline & $\alpha_{1}$ & $1.53 \mathrm{E}-05$ & $1.43 \mathrm{E}-05$ & \\
\hline & $\alpha_{2}$ & $1 \mathrm{E}-08$ & ----- & \\
\hline & $\beta_{1}$ & 0.01167 & 0.01277 & \\
\hline & $\beta_{2}$ & 0.1885 & 0.3575 & \\
\hline
\end{tabular}

\subsection{Value at Risk}

Before calculating the Value at Risk value from the GJR GARCH (1.1) model. we calculated the GJR GARCH (1.1) at the 95\% confidence level with $\alpha=5 \%$ will be used in calculating the GJR GARCH volatility value so that the $Z(1-\alpha)$ value is 1.645 . The GJR GARCH (1.1) volatility value is obtained from the square root of the variance as follows:

$$
\sigma_{t}^{2}=0,0000139+0.009961 \varepsilon_{t-1}^{2}+0.99472 \sigma_{t-1}^{2}+I_{t-1} \varepsilon_{t-1}^{2}
$$

$\sigma_{t}=0.02039611$

then we calculate with the GJR-GARCH (1.1) model as follows:

$$
\begin{aligned}
\operatorname{VaR}_{t} & =\mu+\sigma_{t} \Phi^{-1}(\alpha) \\
\operatorname{VaR}_{t} & =2.218 \mathrm{e}^{-20}+(0.02039611)(1.645) \\
\operatorname{VaR}_{t} & =0.03355161
\end{aligned}
$$

We obtain VaR at a $95 \%$ confidence level of 0.03355161 or a percentage of $3.335 \%$ of current assets.
For example if it is assumed that an investor has a capital of IDR100.000.000 then the maximum loss obtained in the next day is IDR3.335.000.

\subsection{Average Value at Risk}

Estimation of the AVaR value using the GJR GARCH model (1.1) at the $95 \%$ confidence level is

$$
\begin{aligned}
A V a R & =-E\left(r_{t} \mid r_{t-1}<\operatorname{VaR} R_{\alpha}\left(r_{t}\right)\right) \\
& =0.001627795
\end{aligned}
$$

\section{CONCLUSION}

The results of the calculation of the estimated AVaR value of 0.001627795 at the $95 \%$ confidence level. This means that at $5 \%$ the risk that cannot be calculated by $\mathrm{VaR}$ is calculated by $\mathrm{AVaR}$ by showing the risk of loss experienced in the next day of $0.1627 \%$ of the current asset. For example assuming an investor has a capital of IDR100.000.000 then the loss that may be experienced in the next day with a $95 \%$ confidence level is IDR 162.779.00. 


\section{REFERENCES}

[1] Komang D 2015 Estimasi Nilai AVaR Menggunakan Model GJR dan Model GARCH Jurnal Matematika. 5(2) 117-127

[2] Robert E 2001 GARCH 101: The Use of ARCH/GARCH Models in Applied Econometrics $J$. Econ. Perspect. 15(4) 157-168

[3] Lawrence R G. Ravi G. and David E D 1993 On the Relation between the Expected Value and the Volatility of the Nominal Excess Return on Stocks J. Finance. 48(5) 1779-1801.

[4] Tim B 1986 Generalized Autoregressive Conditional Heteroskedasticity J. Econom. 31(3) 307-327

[5] Dinul D J 2017 Perbandingan Model Glosten. Jagannathan and Runkle-Generalized Autoregressive Conditional Heterscedasticity(GJRGARCH) dan Exponential Generalized Autoregressive Conditional Heteroscedasticity (EGARCH) dalam Analisis Risiko Saham Syariah. Undergraduate Thesis. Universitas Islam Negeri Sunan Kalijaga Indonesia: Yogyakarta

[6] Komang T B M 2015 Model Non liniear NGARCH untuk mengestimasi nilai Value at Risk (VaR) pada IHSG E-Jurnal Matematika 4(2) 59-66

[7] Mohammad F Q 2013 Analisis Portofolio Optimum Saham Syariah dan Prospeknya Menggunakan Value at Risk-Capital Asset Pricing model (VaR$C A P M)$ dalam rangka Pengembangan Pasar Modal Syariah di Indonesia. [online] Available at: http://digilib.uin-suka.ac.id/11961/. [Accessed 22 October 2020]. 